\title{
A study on clinical profile of indoor patients receiving anti-tuberculosis treatment at KPC Medical College and Hospital, Kolkata, India
}

\author{
Shilpa Karir ${ }^{1}$, Atanu Biswas ${ }^{1}$, Asok Kumar Mandal ${ }^{1}$, Vidya Sagar ${ }^{2}$, Moumita Pal ${ }^{3}$
}

\begin{abstract}
${ }^{1}$ Department of Community Medicine, KPC Medical College, and Hospital, Kolkata, West Bengal, India
${ }^{2}$ Department of Community Medicine, Rajendra Institute of Medical Sciences, Ranchi, Jharkhand, India

${ }^{3}$ Department of Community Medicine, ICARE Institute of Medical Sciences and Research, Haldia, Purba Medinipur,

West Bengal, India
\end{abstract}

Received: 09 August 2016

Accepted: 06 September 2016

\author{
*Correspondence: \\ Dr. Shilpa Karir, \\ E-mail: drshilpa011@gmail.com
}

Copyright: (c) the author(s), publisher and licensee Medip Academy. This is an open-access article distributed under the terms of the Creative Commons Attribution Non-Commercial License, which permits unrestricted non-commercial use, distribution, and reproduction in any medium, provided the original work is properly cited.

\begin{abstract}
Background: India is the biggest contributor of TB cases globally. About 2.5 million prevalent cases and 0.22 million deaths from the disease were reported in India in 2015. The objective of this study was to assess the sociodemographic and clinical profile of the indoor patients receiving treatment from the DOTS centre of KPC Medical College and Hospital, Kolkata, India.

Methods: An observational, descriptive, record based study was conducted on TB patients admitted in indoor wards under various departments of KPC Medical College and Hospital. Data were analyzed using IBM SPSS (version 20).

Results: Of 80 study subjects, $73.8 \%$ were male and $25 \%$ belonged to 20-30 years age group. Records reflected $41.3 \%$ subjects had pulmonary $\mathrm{TB}, 51.2 \%$ had extrapulmonary $\mathrm{TB}$ and the rest had both pulmonary and extrapulmonary TB. New cases comprised $91.3 \%$ subjects and previously treated cases were $8.7 \%$ subjects. HIV status was negative in $67.5 \%$ subjects and records were unavailable in $32.5 \%$ subjects. Diabetes was present in $27.5 \%$ subjects, negative in $67.5 \%$ and information was unavailable in 5\% cases. Among the patients with known Diabetes status, the result of association between TB-Diabetes and gender of the subjects was found to be statistically significant.

Conclusions: Information regarding occupation, investigations other than sputum test, HIV and Diabetes status were not mentioned in some treatment cards; hence emphasis should be given on proper record maintenance. Awareness generation and proper counseling on TB-HIV co-infection among all the patients should be focused on so that all the patient's turn up for HIV testing.
\end{abstract}

Keywords: Tuberculosis, Anti-tuberculosis treatment, Clinical profile

\section{INTRODUCTION}

Tuberculosis (TB), caused by Mycobacterium tuberculosis, is one of the major public health problems globally.

Pulmonary tuberculosis (PTB) accounts for about $85 \%$ cases, while Extra-pulmonary tuberculosis (EPTB) can involve bones and joints, intestines, meninges, lymph nodes, genitourinary tract, skin and other parts of the body. This disease is not only a chronic disease, but can also be fatal unless managed in time. India, even though is the second most populous country in the world, is the biggest burden of TB globally.

WHO Global TB Report 2015 shows annually there are 9.6 million incidence cases globally in 2015 , of which India alone contributed 2.2 million incidence cases. About 2.5 million prevalent cases and 0.22 million deaths from the disease were reported in India in $2015^{1}$ 
After the introduction of National Tuberculosis Control Programme (NTP), followed by Revised National Tuberculosis Control Programme (RNTCP) with Directly Observed Treatment Short-Course chemotherapy (DOTS) strategy in 1997, there has been a steady decline in prevalence and death from TB in India. As compared to 1990 , by 2013 there was a reduction of $50 \%$ mortality and $55 \%$ prevalence. $^{2}$

Annual Status Report 2016 shows, in 2015, total 58,408 patients were diagnosed with smear positive PTB, 87,468 patients were registered for treatment, $85 \%$ new smear positive cases were cured, 1,78,166 retreatment cases were registered and $68 \%$ of retreatment relapse smear positive cases were cured in the state of West Bengal. ${ }^{1}$

Tuberculosis affects people across all age groups, but more commonly young adult males. Apart from socioeconomic factors, one of the most important contributing factors leading to causation of $\mathrm{TB}$ is suppressed immunity. Infections (e.g. HIV), chronic diseases (e.g. diabetes), immunosuppressive therapy (cancer chemotherapy, steroid therapy) etc. can lead to reduced immunity that puts a person at higher risk to develop the disease.

Tuberculosis is one of the most common opportunistic infections in HIV/AIDS. In 2013, total of 1,063,644 HIV patients were screened for TB and 44,027 HIV positive patients were reported to have TB in India. ${ }^{3,4}$ In 2015, total number of new cases of TB along with HIV was 30,988 (13\% death) in India and 826 (15\% death) in West Bengal, while total number of retreatment cases along with HIV was 13,269 (14\% death) in India and 406 (13\% death) in West Bengal. People with HIV-TB co-infection need prompt initiation of Anti-Tubercular treatment, since not only it can cure TB in the patient, but it can also add years to the lives of the PLHIVs. ${ }^{1}$

RNTCP has been recognized as the largest and fastest growing TB control programme in the world. Focusing on quality sputum examination for early diagnosis of TB cases followed by judicious use of Anti-Tubercular Drugs (ATDs), under DOTS, have not only increased the proportion of TB cases being detected and cured, but also decelerated the emergence of Multidrug Resistance TB (MDR-TB) and Extensive Drug Resistance TB (XDRTB).

RNTCP and National AIDS Control Programme (NACP) have been working hand in hand for cross reference between Integrated Counseling and Testing centres (ICTC) and RNTCP diagnostic and treatment services to decrease the burden of HIV-TB co-infection.

Designated Microscopy Centres (DMC) and DOTS centres across the country have been functioning under expert supervision, along with continuous monitoring and evaluation, with a common goal to achieve a status of 'Tuberculosis free India'. In the year of 2015, at DMC of
KPCMCH, Kolkata a total 1007 TB suspects had undergone sputum examination for diagnosis, sputum positive TB was found in 72 patients, sputum negative TB in 21 patients and 79 patients were diagnosed to have extrapulmonary TB.

In last seven years (2009-2015), 5575 TB suspects had undergone sputum examination for diagnosis at DMC, $\mathrm{KPCMCH}$. In this context, our study has embarked upon assessing the socio-demographic and clinical profile of the indoor admitted patients who were receiving ATD from the DOTS centre of KPC Medical College and Hospital (KPCMCH), Kolkata, India.

\section{METHODS}

An observational, descriptive, record based study was conducted on socio-demographic and clinical profile of TB patients admitted in indoor wards under various departments of KPC Medical College and Hospital. These patients were registered and were receiving antitubercular treatment from the DOTS centre of $\mathrm{KPCMCH}$, under RNTCP. The RNTCP treatment cards of the patients admitted in different wards were used as study tool for secondary data analysis.

All the patients who had begun their treatment at DOTS centre, KPCMCH, between $1^{\text {st }}$ May 2015 and 30th April 2016 (a period of one year), were considered as the study subjects. There were total of 80 study subjects who had begun treatment in the said duration. Parameters regarding socio-demographic profile include age, sex, district of stay and occupation.

Study variables about clinical profile include type of disease, investigations conducted, sputum examination result, type of patient, category of treatment etc. available information on comorbidities of TB, like HIV/AIDS, Diabetes were also noted. Case definitions, treatment outcome definitions and other protocols have been followed as per WHO guidelines, revised on 2013 (updated on December 2014). The data were analyzed using IBM SPSS (version 20).

\section{RESULTS}

The secondary data analysis of the treatment card of 80 patients receiving treatment from DOTS centre of KPCMCH showed that $59(73.8 \%)$ study subjects were male and $21(26.2 \%)$ subjects were female. Most of them (20 subjects, $25 \%$ ) belonged to $20-30$ years followed by $16(20 \%)$ subjects in 50-60 years and only one subject (a child aged 2 years) belonged to $0-10$ years age group.

In this study, $12(15 \%)$ subjects were students, 11 $(13.7 \%)$ subjects were retired, $16(20 \%)$ subjects were housewives and $9(11.2 \%)$ had business as their occupation. Information regarding occupation status of 5 $(6.2 \%)$ was not mentioned in the treatment card (Table 1). Majority of the patients (46 subjects, 57.5\%) were 
from Kolkata, followed by 23 (28.8\%) from 24 Parganas (South) and 5 (6.3\%) from 24 Parganas (North), which are the nearby districts of Kolkata (Figure 1).

Table 1: Distribution of study subjects according to socio-demographic profile.

\begin{tabular}{|lll|}
\hline $\begin{array}{l}\text { Socio-demographic } \\
\text { profile }\end{array}$ & $\begin{array}{l}\text { Frequency } \\
(\mathbf{n = 8 0})\end{array}$ & Percentage \\
\hline Gender & & \\
\hline Male & 59 & 73.8 \\
\hline Female & 21 & 26.2 \\
\hline Age group (years) & & \\
\hline $0-10$ & 1 & 1.3 \\
\hline $10-20$ & 3 & 3.8 \\
\hline $20-30$ & 20 & 25.0 \\
\hline $30-40$ & 13 & 16.3 \\
\hline $40-50$ & 10 & 12.5 \\
\hline $50-60$ & 16 & 20.0 \\
\hline $60-70$ & 9 & 11.2 \\
\hline $70-80$ & 6 & 7.5 \\
\hline $80-90$ & 2 & 2.5 \\
\hline Occupation & & \\
\hline Service & 5 & 6.2 \\
\hline Laborer & 7 & 8.8 \\
\hline Driver & 3 & 3.7 \\
\hline Farmer & 2 & 2.5 \\
\hline Housewife & 16 & 20.0 \\
\hline Business & 9 & 11.2 \\
\hline Rickshaw puller & 1 & 1.3 \\
\hline Student & 12 & 15.0 \\
\hline Unemployed & 4 & 5.0 \\
\hline Retired & 11 & 13.7 \\
\hline Professional & 3 & 6.2 \\
\hline Maid servant & 1 & \\
\hline Guard & 5 & 1.3 \\
\hline Record not available & & \\
\hline & & \\
\hline
\end{tabular}

Table 2: Distribution of study subjects according to disease profile.

\begin{tabular}{|lll|}
\hline Disease profile & \multicolumn{1}{c|}{ Frequency } & Percentage \\
\hline Disease classification $(\mathbf{n = 8 0})$ & \\
\hline Pulmonary & 33 & 41.3 \\
\hline Extrapulmonary & 41 & 51.2 \\
\hline $\begin{array}{l}\text { Pulmonary + } \\
\text { Extrapulmonary }\end{array}$ & 6 & 7.5 \\
\hline \multicolumn{2}{|l|}{ Type of extrapulmonary } & TB $(\mathbf{n}=\mathbf{4 9}) *$ \\
\hline Pleural effusion & 36 & 73.5 \\
\hline Hydropneumothorax & 2 & 4.2 \\
\hline Caries spine & 1 & 2.0 \\
\hline Cold abscess & 1 & 2.0 \\
\hline Pyopneumothorax & 1 & 2.0 \\
\hline Abdominal TB & 8 & 16.3 \\
\hline
\end{tabular}

* Out of 41 subjects with extra-pulmonary TB, few had more than one manifestations.
Table 2 depicts 33 (41.3\%) cases had pulmonary TB, 41 $(51.2 \%)$ cases had extra-pulmonary TB and $6(7.5 \%)$ had both pulmonary and extra-pulmonary TB. Among 41 extra-pulmonary cases, varying features were pleural effusion (36 cases, 73.5\%), abdominal TB (8 cases, $16.3 \%$ ), hydropneumothorax, caries spine, cold abscess and pyopneumothorax.

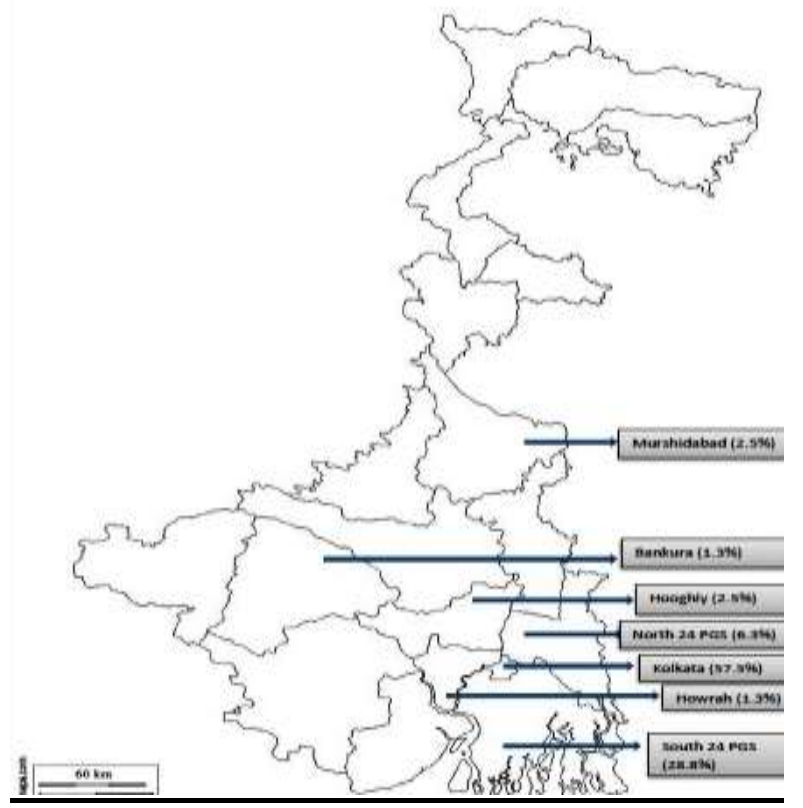

Figure 1: Study subjects from different districts of West Bengal admitted in different departments and receiving treatment under DOTS at $\mathrm{KPCMCH,}$ Kolkata, India.

Table 3 reflects about the sputum smear results of the study subjects. The results were negative in $8(10 \%)$ patients, scanty in $3(3.7 \%)$, ' + ' in $1(1.2 \%)$, ' ++ ' in 6 $(7.5 \%)$ and ' +++ ' in $14(17.5 \%)$ patients. Sputum smear examination was not conducted in 48 cases, among which 41 had extra-pulmonary $\mathrm{TB}$, and in $7(8.8 \%)$ patients treatment was initiated on the basis of Chest X-ray (CXR).

Table 3: Distribution of study subjects according to sputum smear result.

\begin{tabular}{|lll|}
\hline Sputum smear result & $\begin{array}{l}\text { Frequency } \\
(\mathbf{n = 8 0})\end{array}$ & Percentage \\
\hline Negative & 8 & 10.0 \\
\hline Scanty & 3 & 3.7 \\
\hline+ & 1 & 1.2 \\
\hline++ & 6 & 7.5 \\
\hline+++ & 14 & 17.5 \\
\hline Not done & 7 & 8.8 \\
\hline Not applicable* & 41 & 51.3 \\
\hline
\end{tabular}

*Sputum test was not done for extrapulmonary cases 
Table 4 shows different investigations, apart from sputum smear examination, conducted on 80 study subjects. CXR was conducted on $31(38.8 \%)$ subjects, Adenosine Deaminase (ADA) on 17 (21.3\%), both CXR and ADA on $23(28.8 \%)$. Other investigations done were FNAC, MRI, CT scan and USG (Thorax). Information regarding investigations was not mention in treatment cards of 5 (6.3\%) patients. Among 80 study subjects, 73 (91.3\%) were 'New cases' and $7(8.7 \%)$ were 'previously treated' cases. Out of these 7 previously treated cases, $3(3.7 \%)$ were 'treatment after default', 1 (1.3\%) was 'relapse' case and $3(3.7 \%)$ were 'others' cases (Table 5).

Table 4: Distribution of study subjects according to investigations done, other than sputum examination.

\begin{tabular}{|lll|}
\hline Investigations & Frequency $(\mathbf{n = 8 0})$ & Percentage \\
\hline CXR & 31 & 38.8 \\
\hline ADA & 17 & 21.3 \\
\hline CXR +ADA & 23 & 28.8 \\
\hline FNAC + MRI & 1 & 1.2 \\
\hline CT +FNAC + MRI & 1 & 1.2 \\
\hline CXR + FNAC & 1 & 1.2 \\
\hline USG(Thorax) & 1 & 1.2 \\
\hline Not mentioned & 5 & 6.3 \\
\hline
\end{tabular}

Table 5: Distribution of study subjects according to types of patients.

\begin{tabular}{|lll|}
\hline Types of patients & $\begin{array}{l}\text { Frequency } \\
(\mathbf{n = 8 0})\end{array}$ & Percentage \\
\hline New & 73 & 91.3 \\
\hline Treatment after default & 3 & 3.7 \\
\hline Relapse & 1 & 1.3 \\
\hline Transfer in & 0 & 0 \\
\hline Treatment failure & 0 & 0 \\
\hline Others & 3 & 3.7 \\
\hline
\end{tabular}

In the present study, out of 73 'New' cases who were receiving Cat-I, 71 (88.8\%) were on Intensive Phase (IP) and $2(2.5 \%)$ were on Continuation Phase (CP). All the 7 'Previously treated' cases were on IP of Cat-II (Table 6).

Table 6: Distribution of study subjects according to type of treatment under DOTS.

\begin{tabular}{|lll|}
\hline Type of treatment & Frequency $(\mathbf{n = 8 0})$ & Percentage \\
\hline Category I & & \\
\hline IP & 71 & 88.8 \\
\hline CP & 2 & 2.5 \\
\hline Category II & & \\
\hline IP & 7 & 8.7 \\
\hline CP & 0 & 0 \\
\hline
\end{tabular}

All the study subjects were referred to ICTC for HIV testing. Among 80 subjects, $54(67.5 \%)$ had negative HIV result while record of HIV testing was not available for $26(32.5 \%)$ subjects.
The reason of unavailability of HIV reports in these 26 subjects being noncompliance (patients didn't turn up for the test) in 21 subjects and pending reports in 5 subjects (Table 7). The status of Diabetes was assessed in the study subjects and the results were positive in 22 $(27.5 \%)$, negative in $54(67.5 \%)$. Diabetes status was not mentioned for $4(5 \%)$ patients because of pending results (Table 8).

\section{Table 7: Distribution of study subjects according to HIV serology report.}

\begin{tabular}{|lll|}
\hline HIV report & Frequency $(\mathbf{n = 8 0})$ & Percentage \\
\hline Negative & 54 & 67.5 \\
\hline Not available* & 26 & 32.5 \\
\hline
\end{tabular}

*Reports were pending for 5 study subjects and the rest 21 subjects did not turn up for HIV testing.

Among the patients with known Diabetes status (76 subjects), the result of association between TB-Diabetes and sex of the subjects was found to be statistically significant (Chi square value 5.323, $\mathrm{P}=0.02$ ) (Table 9).

Table 8: Distribution of study subjects according to presence of diabetes.

\begin{tabular}{|lll|}
\hline Diabetes status & $\begin{array}{l}\text { Frequency } \\
(\mathbf{n = 8 0})\end{array}$ & Percentage \\
\hline Present & 22 & 27.5 \\
\hline Absent & 54 & 67.5 \\
\hline Record not available* & 4 & 5.0 \\
\hline
\end{tabular}

*Reports were pending for 4 study subjects.

Among 80 subjects receiving treatment at DOTS centre, KPCMCH, 2 patients $(2.5 \%)$ had household contacts less than 6 years. But none of them were receiving chemoprophylaxis against TB.

Table 9: Association between gender and diabetes status of the study subjects $(\mathrm{N}=76)$.

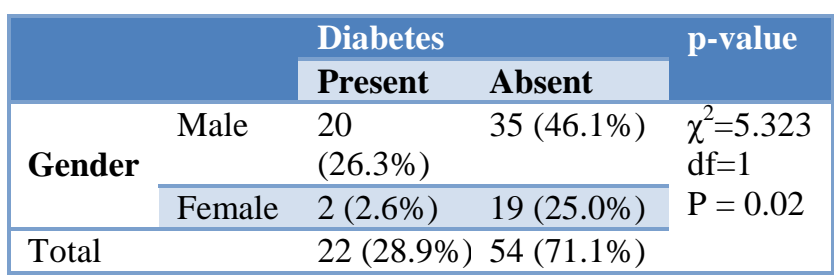

\section{DISCUSSION}

TB was declared a global emergency in the year 1993; recently the Director General of WHO declared AIDS to be a global emergency as well. There exists a synergistic relationship between TB and HIV. ${ }^{4}$

In the present study; most of the subjects $(73.8 \%)$ were male. Similar observations were found in studies conducted by Jethani $\mathrm{S}$ et al. where $74.8 \%$ were male, Sumana M et al. (70.5\% male), Sunderam $\mathrm{S}$ et al. (71.1\% 
male) and Christian D et al. (68\% male) $)^{5-8}$ This finding is in accordance with the statement that TB is more prevalent among male than female. ' In this study, maximum subjects were reported in the age group of 20 30 years $(25 \%)$ followed by $50-60$ years $(20 \%)$. Studies reported by Sumana $M$ et al and Jethani $S$ et al revealed most of the subjects were from the age group of 25-44 years $(47.5 \%)$ and $40-49$ years $(18.7 \%)$ respectively. ${ }^{5,6}$ Most of the subjects in the present study were housewives $(20 \%)$, followed by student $(15 \%)$, retired $(13.7 \%)$, laborer $(8.8 \%)$, service $(6.2 \%)$, unemployed (5\%) etc. The study conducted by Christian D et al. mentions occupations like laborer (46\%), home based work (16\%), service (14\%), unemployed (14\%) etc. among the study subjects. ${ }^{8}$

The study conducted at DOTS clinic of KPCMCH revealed that $41.3 \%$ subjects had pulmonary TB, $51.2 \%$ had extrapulmonary TB and the rest had combination of pulmonary and extrapulmonary diseases. Similar observations were reported by Prakash BC et al. where extrapulmonary cases $(59.8 \%)$ exceeded pulmonary cases $(40.2 \%) .^{10}$

Dey $\mathrm{D}$ et al. in their study mentioned pulmonary cases being $89.3 \%$ and extrapulmonary as $10.7 \% .{ }^{11}$ Overall, in our study, the total number of different types of EPTB cases included pleural effusion $(73.5 \%)$, followed by abdominal TB (16.3\%), hydropneumothorax (4.2\%), and the rest being caries spine, cold abscess and pyopneumothorax each being $2 \%$.

Different types of extrapulmonary involvement, as found in study conducted by Prakasha SR et al. were pleura (28\%), lymph node $(24.8 \%)$, CNS $(12.5 \%)$, bones and joints $(12.3 \%)$, abdomen $(9.7 \%)$, and others $(12.7 \%)$ which included genitourinary, skin, pericardium and breast lump. ${ }^{12}$ Similar observations were found by Mavila $\mathrm{R}$ et al. where extrapulmonary manifestation were lymph node $(29.4 \%)$, gastrointestinal (24\%), pleura (23.5\%), skeletal $(7.5 \%)$ and others. ${ }^{13}$

The sputum smear results of the study subjects at DOTS clinic, $\mathrm{KPCMCH}$, reflected that the results were negative in $10 \%$ patients, scanty in $3.7 \%$, ' + ' in $1.2 \%$, ' ++ ' in $7.5 \%$ and ' +++ ' in $17.5 \%$ patients. A study conducted at Midnapur district, West Bengal, by Dey D et al. showed that sputum grade at diagnosis were scanty (6.9\%), negative $(19.3 \%)$, '+' (44.4\%), '++' $(12.1 \%)$ and ' +++ ' $(17.4 \%) .{ }^{11}$ Pre-treatment sputum results of treatment failure cases, in a study conducted by Mukhopadhyay $\mathrm{S}$ et al. were scanty (17.8\%), '+' (37.6\%)', '++' (23.8\%) and ' +++ ' $(20.8 \%) .{ }^{14}$

In present study $91.3 \%$ subjects were receiving Category I and rest $8.7 \%$ were on Category II treatment. Similar observations were reported by Dey D et al $(89.3 \%$ Cat I; $10.7 \%$ Cat II) and Raghuraman S et al $(74.2 \%$ Cat I; $25.8 \%$ Cat II). ${ }^{11,15}$ The study conducted by Dey D et al. reported that out of 363 study subjects with TB, the HIV status was positive in $3.9 \% .^{11}$

Another study conducted by Shrivastava SR et al. showed $10.2 \%$ of subjects with positive HIV status. ${ }^{16}$ Observations in our study reflected that HIV status was negative in $67.5 \%$ patients. For the rest $26(32.5 \%)$ patients, the HIV status was not known. All the patients who were diagnosed to have Tuberculosis were referred to ICTC for HIV testing as per RNTCP guidelines. The reasons of unavailability of the HIV report in these 26 patients were pending reports in 5 patients and noncompliance in 21 patients. These noncompliant patients did not turn up for HIV testing at ICTC, $\mathrm{KPCMCH}$.

Blood sugar level was assessed in all subjects attending the DOTS centre, KPCMCH. Diabetes status was positive in $27.5 \%$ subjects. Among the patients with known Diabetes status (76 subjects), the result of association between TB-Diabetes and sex of the subjects was found to be statistically significant (Chi square value 5.323, $\mathrm{P}=0.02$ ). Similar observations were reported in the study conducted by Dey D et al. with $12.4 \%$ subjects with Diabetes and association between TB-Diabetes and sex being statistically significant (Chi square value 5.69, $\mathrm{P}=0.02) .{ }^{11}$ Studies conducted by Prakash BC et al and Raghuraman $\mathrm{S}$ et al revealed presence of Diabetes in $9.2 \%$ and $29.03 \%$ subjects with TB respectively. ${ }^{10,16}$

In the present study, 2 subjects $(2.5 \%)$ had household contacts less than 6 years, but none of them were receiving chemoprophylaxis against $\mathrm{TB}$. The role of Isoniazid (INH) chemoprophylaxis, especially in developing countries like India, is doubtful because of its high cost, less effectiveness and risk of developing drug induced hepatitis, and thus not a worthwhile exercise for TB control. ${ }^{9}$

\section{CONCLUSION}

The present study, conducted at the DOTS centre of $\mathrm{KPCMCH}$, was based on secondary data analysis of RNTCP treatment cards of indoor admitted patients and had its limitations. Data regarding occupation status and diagnostic procedure in extrapulmonary TB were missing for few cases. Thus, emphasis should be given on proper record maintenance. In 7 cases, ATD was initiated prior to sputum examination on the basis of clinical features and X-ray findings. Hence pre-treatment sputum examination results were not mentioned in treatment cards of these patients.

All the 80 study subjects were referred to ICTC for HIV testing, but 21 patients did not turn up for the test. Thus, awareness generation and proper counseling on TB-HIV co-infection among all the patients should be focused on to ensure $100 \%$ cross-referral between ICTC and RNTCP for diagnostic and treatment services. 


\section{ACKNOWLEDGEMENTS}

Authors would like to acknowledge Dr. Abhijit $\mathrm{Kr}$ Ghosh, MO RNTCP and Mr. Sudeep Chatterjee, TBHP for their cooperation.

Funding: No funding sources Conflict of interest: None declared

Ethical approval: The study was approved by the Institutional Ethics Committee

\section{REFERENCES}

1. TB India 2016. Revised National TB Control Programme Annual Status Report. Central TB Division; March 2016 [cited 15th July 2016]. Available from: http://www.tbcindia.gov.in

2. Taneja DK. Health Policies and Programmes in India. Revised National Tuberculosis Control Programme. 14th ed. Delhi: Doctors Publication; 2016:213.

3. Giri PA, Deshpande JD, Phalke DB. Prevalence of pulmonary tuberculosis among HIV positive patients attending antiretroviral therapy clinic. North Am J Med Sci. 2013;5:367-70.

4. WHO 2014. Global Tuberculosis Report 2014.

5. Jethani S, Kakkar R, Semwal J, Rawat J. Sociodemographic Profile of Tuberculosis Patient : A Hospital Based Study at Dehradun. Nat J Com Med. 2014;5(1):6-9.

6. Sumana M, Sreelatha CY, Renuka M, Ishwaraprasad GD. Patient and health system delays in diagnosis and treatment of tuberculosis patients in an urban tuberculosis unit of south India. Int J Community Med Public Health. 2016;3:796-804.

7. Sunderam S, Kumari S, Haider S, Kashyap V, Singh S. A study on socio demographic profile of patients having cough of two weeks or, more along with their smear microscopy outcome attending a Tertiary Care Hospital of Jharkhand, India. IJIMS. 2015;2(5):119-27.

8. Christian D, Singh US, Mukherjee S, Sharma D. Socio-demographic profiles of the delayed diagnosed patients in RNTCP, Anand District. Healthline. 2010;1(1):45-8.

9. Park K. Park's Textbook of Preventive and Social Medicine. Tuberculosis. Epidemiology of Communicable Diseases. 23 ${ }^{\text {rd }}$ Ed. Jabalpur: Bhanot publishers. 2015.

10. Prakash BC, Ravish KS, Prabhakar B, Ranganath TS, Naik B, Satyanarayana S, et al. Tuberculosisdiabetes mellitus bidirectional screening at a tertiary care centre, South India. 2013;3(1):s18-22.

11. Dey D, Patra BC, Ghosh D. HIV seroprevalence among Tuberculosis patients in East Midnapore district of West Bengal, India. International journal of Current research. 2015;7(5):15582-5.

12. Prakasha SR, Suresh G, D'sa IP, Shetty SS, Kumar SG. Mapping the Trend and Pattern of Extrapulmonary Tuberculosis. J Glob Infe Dis. 2013;5(2):54-9.

13. Mavila R, Kottarath M, Nair S, Thaha M. Site predilection of extrapulmonary tuberculosis: study from a tertiary care centre. IJRMS. 2015;3(11):3386-90.

14. Mukhopadhyay S, Sarkar AP, Sarkar S. A Study on Factors Influencing Treatment Outcome of Failure Patients Receiving DOTS in a District of West Bengal. Ind Jou PubHealth. 2010;54(1):21-3.

15. Raghuraman S, Vasudevan KP, Govindarajan S, Chinnakali P, Panigrahi KC. Prevalence of Diabetes Mellitus among Tuberculosis patients in urban Puducherry. Nor Ame J Med Sci. 2014;6(1):30-4.

16. Shrivastava SR, Shrivastava PS. HIV-tuberculosis interface: a comparison of collateral prevalence of HIV and tuberculosis in an urban health centre. An Tro Med Pub Health. 2013;6:290-6.

Cite this article as: Karir S, Biswas A, Mandal AK, Sagar V, Pal M. A study on clinical profile of indoor patients receiving anti-tuberculosis treatment at KPC Medical College and Hospital, Kolkata, India. Int J Community Med Public Health 2016;3:2891-6. 